\title{
Modeling and Simulation of Fresh Air System with LHTS and Solar Energy
}

\author{
Wang Lili \\ College of Automation Electronic Engineering, \\ Qingdao University of Sciences and Technology \\ Qingdao, China
}

\begin{abstract}
State of the research about the technology of solar energy with LHTS (Latent Heat Thermal Storage ) at home and abroad was firstly introduced, and a fresh air system with solar energy and LHTS was then introduced. After that the fuzzy control system of fresh air temperature was studied. Firstly, a mathematical model of the fan coil was built as the controlled plant. Then, a fuzzy controller was designed and applied to control the fresh air temperature with the features of high non-linearity, large disturbance and uncertainty of fresh air system. Finally, the simulation was realized on the mathematical model of the fan coil. It proves that the fuzzy control system has a high accuracy in stability and is able to resist interference. This research will be helpful for fuzzy controller design of the fresh air system.
\end{abstract}

Keywords-Solar Energy; LHTS; Fresh Air; Mathematical model; Simulation; Fuzzy controller

\section{INTRODUCTION}

Scholars at abroad have done a lot of research on the combination of solar energy and LHTS technology. In Japan, they did some numerical simulation and research on Charge and Discharge Characteristics of Floor Supply Air Conditioning System including phase change material.

In order to improve the efficiency of collectors, the scholars in Nigeria reduced the convection heat loss inside the collectors by adding a paraffin to form-stable phase change material (PCM).

Additionally, Chow, T.T from Hong Kong University performed some simulation analysis on photovoltaic system using finite difference method and Control Volume Method. According to daily efficiency of the solar collectors, it is proved that the model matches perfectly with the experimental data. Koca, Ahmet stored the heat energy of solar collectors in the Thermal Storage Using $\mathrm{CaCl} 2 \cdot 6 \mathrm{H} 2 \mathrm{O}$ as phase change material, and the energy efficiency and exergy efficiency is respectively $45 \%$ and $2.2 \%$ [1 4].

It is proved that there is surely advantage of energy saving and environment protection for the solar energy storage technology. And then, the technology will be used more and more widely in the future. However, there is little study about it in china.

Consequently, a fresh air system with solar collectors and LHTS tank was firstly introduced, and then the control strategy according to the characteristics of the system was studied.

\author{
Zhang Tao \\ College of Automation Electronic Engineering \\ Qingdao University of Sciences and Technology \\ Qingdao, China
}

I MEASURING AUTOBODY PANELS

The fresh air system with solar collectors and LHTS tank filled with Phase Change Material is shown as Figure.1. The solar collector converts the heat from sunlight into the heat of the water in the pipes, and then the heated water can flow according to the control modes set by the system through changing the state of the pump and valves. The heat can be stored in the LHTS tank or used to make the heat transfer with the fresh air to play a fresh air heating, heat storage role of the auxiliary room.

To simulate the operation of the solar during a day, three control modes are determined in accordance with the solar radiation and the heat collected from the solar over time. The overall operating modes are, Mode I: the solar energy is fully for the fresh air. Mode II: the solar energy is part for fresh air and part for storage of the LHTS tank. Mode III: the LHTS tank is fully for the fresh air. Take Mode II as example which is depicted in Figure 2, of which the red lines denote the inlet of the heated water, while the blue lines denote the outlet water after the heat transfer.

From Figure2, we can see that one part of the water after heated by the solar collectors flows through the fan coil which is used to make the heat transfer with the cool air; the other part is used to store in the LHTS tank which will be used to heat the cool air when there is not enough solar energy for fresh air

\section{Mathematical Model Of The Fan CoIL (FC)}

Fan coil is the end equipment of the fresh air system, through which the heat transfer is made between hot water and fresh air. In the case of certain structure, heat transfer area and mass flow, the main heat exchange of the fan coil depends on inlet temperature of the hot water and the fresh air.

The parameters of the fan coil are affected by many factors such as outdoor environmental temperature, the solar radiation, etc. It will be quite difficult and impossible to build the exact mathematical model to some extent due to the complexity of the system.

Consequently, any other uncontrolled inputs are not taken into account in this simplified model:

(1) Dry air and water vapor in the air are considered as ideal gas, and the changes of the fluid density and specific heat are both ignored; 
(2) Uniform air flows through the coil heat exchanger, and the heat transfer coefficient is constant whose value only changes with the fluid flow; same

(3) The inlet and outlet air flow of the fan coil are the

(4) The affect between two adjacent tubes of the fan coil is ignored. The temperature of the water in the pipe changes with the direction along the pipe length, while the temperature distribution along the radial direction is uniform.

The Schematic of the Fan Coil is shown as Figure3:

The equation of a room model shown in Figure. 3 can be derived by applying the principle of energy balance

$$
c_{f c} \frac{d T_{a o}}{d t}=\partial_{a}\left(T_{a i}-T_{a o}\right)+\rho_{f} c_{f} w_{f}\left(T_{f i}-T_{f o}\right)+q
$$

where:

$c_{f c} \quad$ Specific heat capacity of overall air conditioning unit $(\mathrm{KJ} / \mathrm{K})$;

$\partial_{a} \quad$ Overall transmittance-area factor $(\mathrm{KJ} / \mathrm{min} . \mathrm{K})$;

$T_{a o} \quad$ outlet temperature of fresh air $\left({ }^{\circ} \mathrm{C}\right)$;

$T_{a i} \quad$ inlet temperature of fresh air $\left({ }^{\circ} \mathrm{C}\right)$;

$\rho_{f} \quad$ Density of water $(1000 \mathrm{Kg} / \mathrm{m} 3)$;

$w_{f}$ flowrate of the water(m3/h);

$c_{f} \quad$ Specific heat capacity of water $\left(\mathrm{J} / \mathrm{Kg} .{ }^{\circ} \mathrm{C}\right)$;

$T_{f i} \quad$ inlet temperature of water $\left({ }^{\circ} \mathrm{C}\right)$;

$T_{f o} \quad$ outlet temperature of water $\left({ }^{\circ} \mathrm{C}\right)$;

$q$ Other heat loss $(\mathrm{KJ} / \mathrm{min})$.

Suppose the outside temperature is constant, that is, its derivative is 0 .

The system state can be decomposed into the stability state and transient state, and each state can be expressed by the steady-state values and transient values. Thus, in order to formulate the system, small variations $\Delta w_{f}$ and $\Delta T_{a o}$ about the operating point must be introduced, such that

$$
\left\{\begin{array}{l}
w_{f}=\overline{w_{f}}+\Delta w_{f} \\
T_{a o}=\overline{T_{a o}}+\Delta T_{a o}
\end{array}\right.
$$

Where, $\overline{T_{a o}}$ and $\overline{w_{f}}$ are a set of steady-state values corresponding to the nominal operating condition. Then (1) can be rewritten in the following form:

$$
\begin{aligned}
& c_{f c} \frac{d \Delta T_{a o}}{d t}=\partial_{a}\left(T_{a i}-\overline{T_{a o}}-\Delta T_{a o}\right)+\rho_{f} c_{f}\left(\overline{w_{f}}+\Delta w_{f}\right) \\
& \left(T_{f i}-T_{f o}\right)+q
\end{aligned}
$$

In the steady-state condition, there is following relationship:

$$
\partial_{a}\left(T_{a i}-\overline{T_{a o}}\right)+\rho_{f} c_{f} \overline{w_{f}}\left(T_{f i}-T_{f o}\right)+q=0
$$

Combine these two equations, (3) becomes

$$
c_{f c} \frac{d \Delta T_{a o}}{d t}=-\partial_{a} \Delta T_{a o}+\rho_{f} c_{f} \Delta w_{f}\left(T_{f i}-T_{f o}\right)
$$

Making Laplace transform of equation (5), we obtain:

$$
c_{f c} s \Delta T_{a o}(s)=-\partial_{a} \Delta T_{a o}(s)+\rho_{f} c_{f} \Delta w_{f}(s)\left(T_{f i}-T_{f o}\right)
$$

Finally, we get the transfer function:

$$
\frac{\Delta T_{a o}(s)}{\Delta w_{f}(s)}=\frac{\rho_{f} c_{f}\left(T_{f i}-T_{f o}\right)}{c_{f c} s+\partial_{a}}
$$

Consequently, the mathematical model of the fan coil can be estimated by first order lag process with dead time.

\section{FuZZY CONTROLLER DESIGN Of FreSh AIR SySTEM}

According to data obtained by manual control, the membership functions of the input and output variables are shown in Figure 4, Figure 5.

The figure indicates that the input variables of the fresh air temperature deviation fielded at $(-1,1)$ is covered by three fuzzy sets. This is because once the system reaches the set value, the control requirements tends to be smaller steadystate error and higher precision. Therefore, the deviation in a small area for fine segmentation gets better control performance.

The domain of fresh air temperature deviation is $(-14$, $10)$, the domain of temperature deviation rate is $(-0.1,0.1)$, the domain of water flow is $(0,1)$.

Fuzzy rules in accordance with the manual control rules are shown in Table.1.

The simulation result is shown in Figure 7 which verifies the feasibility of the fuzzy controller. The fuzzy control system can accurately track the input signal without overshoot and oscillation, and it eventually stabilizes at the set point with fast response.

\section{CONCLUSIONS}

In this paper, a mathematical model of the fan coil in the fresh air system was established. Then a fuzzy controller was designed referring to the manual control data for the characteristics of the nonlinearity, long time delay and timevariable of the fresh air temperature control. Finally, the simulation was accomplished on the mathematical model of the fan coil. It is proved that the fuzzy controller realized in this study can satisfy the controlling requirement of the fresh air system with solar collectors and LHTS tank.

\section{ACKNOWLEDGEMENT}

This work is supported by Startup Foundation for Doctors of Qingdao University of Science and Technology. 


\section{REFERENCES}

[1] S.O. Enibe. Thermal analysis of a natural circulation solarair heater with phase change material energy storage.Renewable Energy, 2003, 18(14): 2269-2299

[2] Chow, T.T. He, W.; Chan, A.L.S.; Fong, K.F.; Lin, Z.; Ji, J. Computer modeling and experimental validation of a building- integrated photovoltaic and water heating system 0 Applied Thermal Engineering, v 28, n 11-12, August 2008, p1356-1364

[3] Weber, R; Dorer, V. Long-term heat storage with $\mathrm{NaOH}$. Vacuum, v 82, n 7-14 March 2008, 708-716

[4] Roonprasang, N. Experimental studies of a new solar water heater system using solar water pump. Energy, v 33, n 4, April 2008, 639746

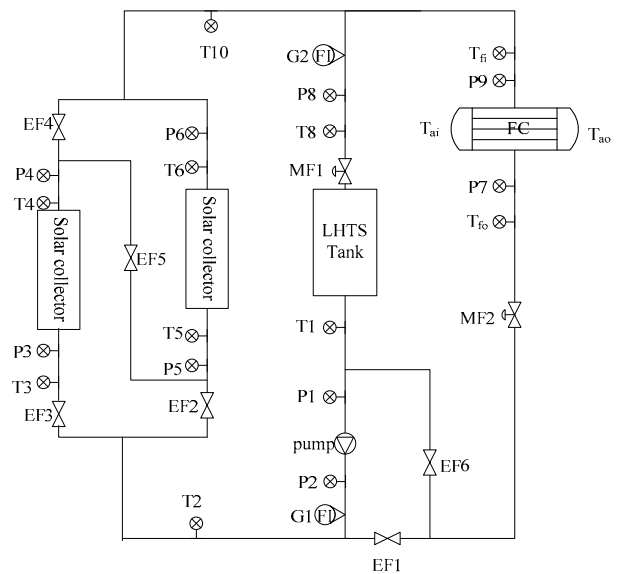

Figure1. Fresh Air system with solar collectors and LHTS tank

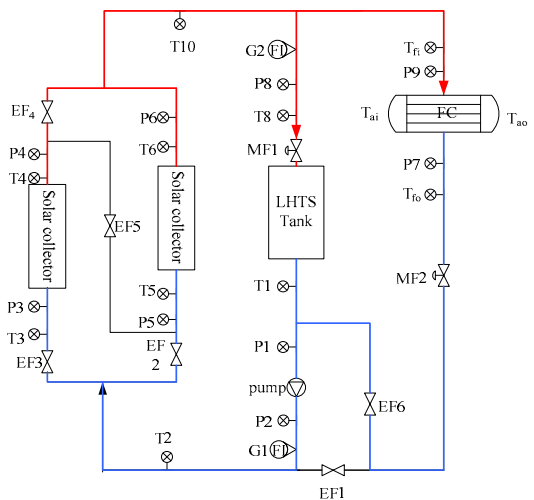

Figure2.solar energy part for fresh air and part for storage of the LHTS tank

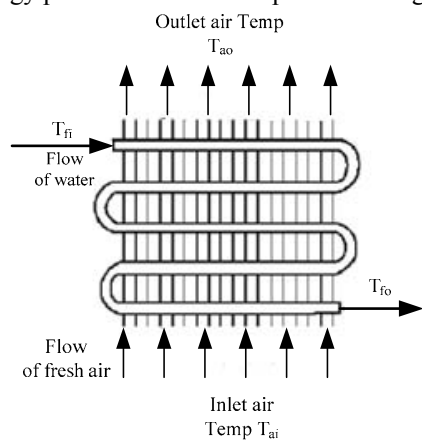

Figure3. heat exchange principle of fan-coil 


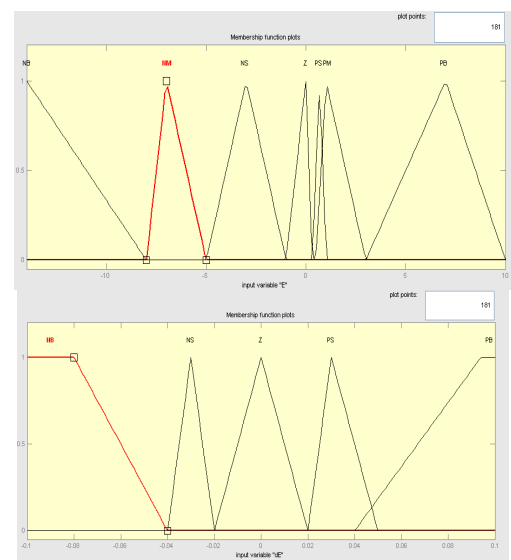

Figure 4. membership function distribution of input variable $\mathrm{E} / \mathrm{dE}$

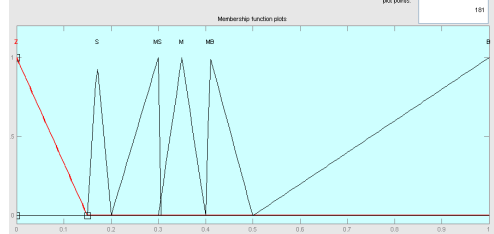

Figure 5. membership function distribution of output variable $\mathrm{Y}$

TABLE I. FUZZY CONTROL RULES

\begin{tabular}{|c|c|c|c|c|c|c|c|c|}
\hline \multicolumn{2}{|c|}{$\mathbf{E}$} & NB & NM & NS & $\mathbf{Z}$ & PS & $\mathbf{P M}$ & PB \\
\hline \multirow[t]{5}{*}{$\mathbf{d E}$} & NB & B & $\mathrm{MB}$ & MB & MB & $\mathrm{S}$ & MS & $\mathrm{S}$ \\
\hline & NS & B & $\mathrm{MB}$ & $\mathrm{MB}$ & $\mathrm{M}$ & MS & MS & $\mathrm{S}$ \\
\hline & $\mathbf{Z}$ & B & $\mathrm{MB}$ & $\mathrm{M}$ & MS & $\mathrm{M}$ & $\mathrm{S}$ & Z \\
\hline & PS & B & $\mathrm{M}$ & MS & $\mathrm{S}$ & $\mathrm{MB}$ & S & Z \\
\hline & PB & MB & MS & S & Z & MB & Z & Z \\
\hline
\end{tabular}

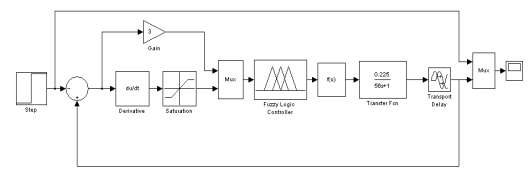

Figure 6. Simulation diagram of the fresh air system

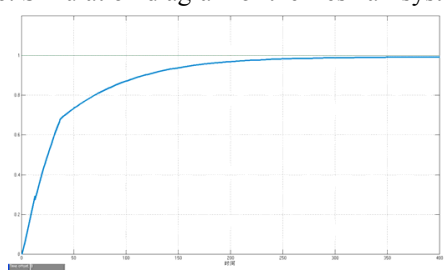

Figure 7. Simulation result of the fresh air system with LHTS and solar energy 